\title{
Aerosols, Climate, and the Hydrological Cycle
}

\author{
V. Ramanathan, ${ }^{1 *}$ P. J. Crutzen, ${ }^{1,2}$ J. T. Kiehl, ${ }^{3}$ D. Rosenfeld ${ }^{4}$
}

\begin{abstract}
Human activities are releasing tiny particles (aerosols) into the atmosphere. These human-made aerosols enhance scattering and absorption of solar radiation. They also produce brighter clouds that are less efficient at releasing precipitation. These in turn lead to large reductions in the amount of solar irradiance reaching Earth's surface, a corresponding increase in solar heating of the atmosphere, changes in the atmospheric temperature structure, suppression of rainfall, and less efficient removal of pollutants. These aerosol effects can lead to a weaker hydrological cycle, which connects directly to availability and quality of fresh water, a major environmental issue of the $21 \mathrm{st}$ century.
\end{abstract}

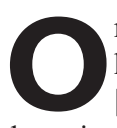
ne of the most visible impacts of human activities is the brownish haze [see Web fig. 1 for anthropogenic haze just south of Mt. Everest (1)] that pervades many industrial regions, as well as the rural areas of the tropics and the subtropics that are subjected to heavy biomass burning. Long-range atmospheric transport transforms this haze into a regional-scale aerosol layer (2). Well-known examples are the Arctic haze, the Indo-Asian haze (Fig. 1), the east Asian dust and haze traveling across the Pacific (Fig. 2, A and B), and the biomass burning and dust plumes from North Africa (Sahara and Sahel regions) that spread over most of the subtropical Atlantic (Fig. 2A). Unlike the long-lived greenhouse gases (GHGs), which are distributed uniformly over the globe, aerosol lifetimes are only a week or less $[(2,3)$, see Web table 1 for representative lifetimes of aerosols (1)], resulting in substantial spatial and temporal variations with peak concentrations near the source (Fig. 2, A and B).

On account of the large spatial and temporal variability of these aerosols, remote sensing from satellites delivers the most reliable information about global aerosol distributions (4). The measurable quantity from space is the aerosol optical depth (AOD) (Fig. 2 ), which is derived from the solar radiation reflected to space (4). The AOD is the vertical integral of the aerosol concentration weighted with the effective cross-sectional area of the particles intercepting (by scattering and absorption) the solar radiation at the wavelength of interest. The globally and annually averaged value of AOD (at $0.55 \mu \mathrm{m}$ )

${ }^{1}$ Scripps Institution of Oceanography, University of California at San Diego, CA 92093, USA. ${ }^{2}$ Max-PlanckInstitute for Chemistry, Mainz, Germany. ${ }^{3}$ National Center for Atmospheric Research, Boulder, CO 80305, USA. ${ }^{4}$ Institute of Earth Sciences, The Hebrew University of Jerusalem, Jerusalem, Israel.

${ }^{*}$ To whom correspondence should be addressed. Email: ram@fiji.ucsd.edu is about $0.12( \pm 0.04)$ [Web table $1(1)$, Fig. $2 \mathrm{~B}$, and $(5,7)]$. Anthropogenic sources contribute almost as much as natural sources to the global AOD (Fig. 2, B and C) $(2,6,7)$. Anthropogenic aerosols are typically in the submicrometer- to micrometer-size range and are composed of numerous inorganic and organic species $(2,3)$, falling under four broad categories [Web table 1 (1)]: sulfates, carbonaceous aerosols [black carbon $(\mathrm{BC})$ and organic carbon (OC)], dust, and sea salt. Global anthropogenic emissions of sulfates, organics, and BC even exceed natural sources [Web table $1(1) ;(2,3)$ ]. Such a large perturbation of the global aerosol loading is a major environmental concern. Here, we ask how aerosols modify regional and global climates.

\section{Radiative Forcing: GHGs and Aerosols}

Greenhouse gases absorb upwelling infrared (IR, also referred to as longwave) radiation and reduce the outgoing long-wave $(>4 \mu \mathrm{m})$ radiation at the top-of-the atmosphere (TOA). The TOA radiative forcing (that is, the change in the outgoing longwave radiation), due to the observed increase in GHGs since the early (8). Aerosols, on the other hand, increase the reflection of solar radiation to space through a variety of complex radiative and microphysical processes (2). The effects of anthropogenic aerosols on long-wave radiation are relatively minor (except for desert dust) and will not be discussed further. Global estimates of the TOA radiative forcing (that is, the change in the absorbed solar radiation) due to anthropogenic aerosols in the solar wavelength region range from -0.5 to $-2.5 \mathrm{~W} \mathrm{~m}^{-2}(3,6,8)$. The negative sign indicates a cooling effect. How do these anthropogenic changes affect the earth radiation 20 th century, is about $2.4 \mathrm{~W} \mathrm{~m}^{-2}$ budget? Qualitatively, looking down on Earth from space, anthropogenic activities are making the planet more absorptive and, as a result, darker with time in the IR and brighter in the visible wavelengths. Satellite radiation budget measurements for 1985 to 1990 indicate $(9)$ that the planet absorbed $238( \pm 2) \mathrm{W}$ $\mathrm{m}^{-2}$ solar radiation and emitted outgoing long-wave radiation of $235( \pm 2) \mathrm{W} \mathrm{m}^{-2}$. The difference of $3 \mathrm{~W} \mathrm{~m}^{-2}$ may be real or an artifact due to measurement errors or a combination of both. If we were to instantaneously reduce (as a hypothetical experiment in thought only) the GHGs and aerosols to the preindustrial values, the outgoing long-wave radiation would increase to $237.4 \mathrm{~W} \mathrm{~m}^{-2}$ $(235+2.4)$, and the absorbed solar radiation would increase to 238.5 to $240.5 \mathrm{~W} \mathrm{~m}^{-2}$ $[238+(0.5$ to 2.5$)]$.

Aerosols also absorb solar radiation, and this solar absorption within the atmosphere, together with the reflection of solar radiation to space, leads to a large reduction in the solar radiation absorbed by the Earth's surface. In the following section, carbonaceous aerosols are identified as playing a major role in this

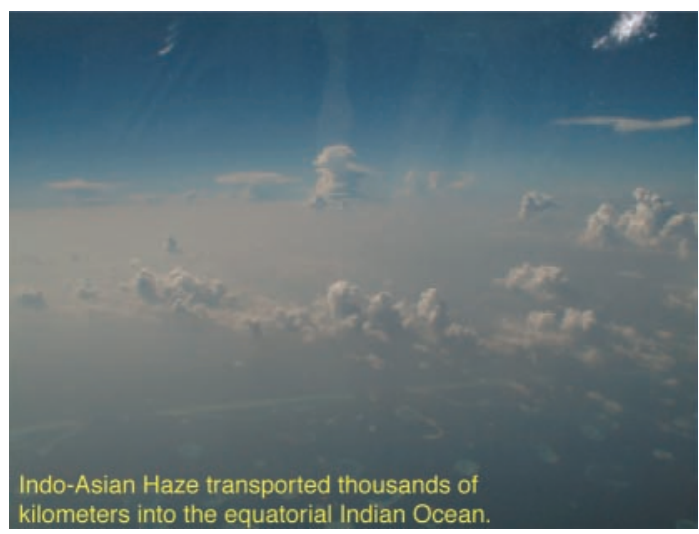

Fig. 1. Clouds in the presence of anthropogenic haze over the equatorial Indian Ocean. Picture taken on 24 February 1999 at $0.5^{\circ} \mathrm{N}, 73.3^{\circ} \mathrm{E}$ during the Indian Ocean Experiment campaign. The brownish haze originates from South Asia (see Web fig. 1 for a photo of thick brownish haze over lower Himalayas). The haze reaches close to the top of cumulus clouds located around $5 \mathrm{~km}$ in this picture.

absorption $(6,8)$. The changes arising from the aerosol scattering and absorption of radiation are referred to as the direct radiative forcing. Aerosols also influence climate in major ways through their important role in cloud condensation and as ice nuclei $(2,3,8)$. Increase in aerosols causes an increase in the droplet number concentration. The increase 


\section{SCIENCE'S COMPASS}

in the number of drops leads to an increase in the reflection to space of solar radiation from clouds, leading to a climate cooling (3). This is called the first indirect radiative forcing. If the condensed moisture inside the cloud is not altered by the increase in aerosols, the droplet radius will decrease because of the increase in its number concentration resulting in a decrease in the precipitation efficiency $(2,3,8)$. This direct microphysical effect
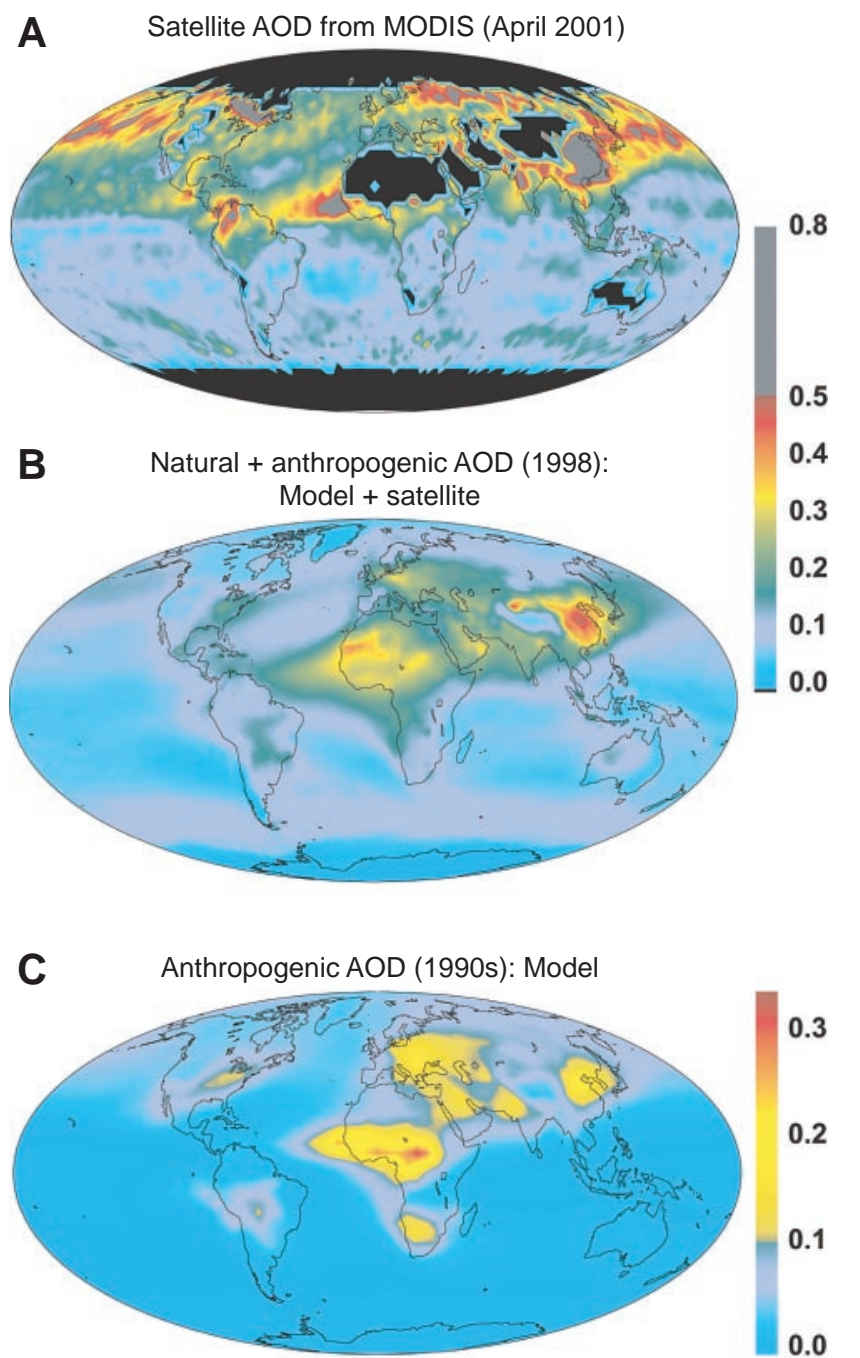

Fig. 2. Global distribution of natural and anthropogenic aerosol optical depth (AOD). (A) AOD at $0.55 \mu \mathrm{m}$ derived from moderateresolution imaging spectrometer, MODIS, on board the TERRA satellite (4). MODIS uses new techniques (4) to derive AOD over the land. Data are shown only for one month. A complete year is still not available. Many land regions are missing (black shaded areas), because these are mostly desert land areas with too bright background for retrieving the AOD. (B) Annual mean AOD (at $0.63 \mu \mathrm{m}$ ) estimated by a four-dimensional assimilation model (5) that uses satellitederived AOD for the oceans to constrain the model AODs. The AOD here represents the sum of natural and anthropogenic aerosol. (C) Anthropogenic contribution to the AOD estimated by a three-dimensional model $(6,7)$. Biomass burning is the major contributor to the high aerosol regions in Africa and South America. Both biomass burning and fossil fuel combustion contribute to the loading in South and Southeast Asia (the model does not capture the full impact of the anthropogenic aerosols in this region). Fossil fuel combustion is the major contributor to the mid- and high latitude aerosol loading. duction in the solar radiation at the surface. As a result, both the surface and the atmosphere will cool, and the magnitude of the cooling can be estimated mostly from the aerosol forcing at the TOA (8).

Carbonaceous aerosols (BC and organics) absorb and scatter solar radiation $(2,3)$. BC has been detected in remote oceanic regions, raising the possibility of hemisphere-wide dispersal (12). The presence of trace amounts of $\mathrm{BC}$ can result in a large atmospheric solar absorption (13), which reduces substantially the solar radiation reaching the surface (14), as shown directly from observations $(15,16)$. In addition, BC absorbs the upward solar radiation (reflected by the surface and clouds). This reduces the solar radiation reflected to space, resulting in a positive TOA aerosol forcing $(6,17)$, in contrast to the negative forcing at the surface. At the TOA, the BC effect opposes the cooling effect of sulfates and organics, whereas at the surface, all aerosols reduce the solar radiation. The net result is that the aerosol-induced changes in the solar radiative flux at the surface (with the possible exception of snow surfaces) far exceed the changes at TOA (16). Whether the Earth's surface will cool or warm in response to the BC forcing will depend on subtle details of how the surface and the atmosphere are coupled together, and as a result, different regions of the planet may respond differently, both in magnitude and in sign. The role of sunlight-absorbing, BC-containing particles on radiative forcing have come to the forefront $(6,8,17)$ in climate-change studies, especially as a result of findings of some major field programs such as Tropospheric Aerosol Radiative Forcing Observational Experiment (18), Smoke, Clouds, and Radiation-Brazil Experiment (19), Aerosol-Characterization Experiment-II (20), and the Indian Ocean Experiment, INDOEX (16, 2123).

\section{Direct Radiative Forcing}

An important parameter that governs the relative scattering and absorption by a particle is the single scattering albedo, SSA, which is the ratio of scattering to the sum of scattering and absorption. The SSA of BC at visible wavelengths is about 0.2 , whereas it is $\sim 1$ for a sulfate aerosol $(2,3)$. The SSAs of most Northern Hemisphere aerosols are in the 0.85 to 0.95 range $(6,17)$. This is interesting because aerosols have a net negative TOA forcing when the SSA exceeds 0.95 , and a net positive TOA forcing for SSAs $<0.85$. For the intermediate values, the net effect can change from negative to large positive forcing depending on the cloud fraction, surface albedo, and the vertical aerosol and cloud distribution (Fig. 3). The global average magnitude and the sign of the TOA direct forcing are therefore 


\section{SCIENCE'S COMPASS}

highly uncertain; it is then not surprising that the global mean TOA aerosol forcing values obtained from publications $(2,3,6$, $8,17)$ range from -0.5 to $+0.2 \mathrm{~W} \mathrm{~m}^{-2}$.

Whereas the forcing at the TOA is the main focus of most studies $(3,8)$, the major outcome of recent field campaigns is the finding that aerosols have a substantially larger impact on the surface and the atmospheric solar radiative heating. The TOA radiative forcing is merely the sum of the surface and the atmospheric radiative forcing. The INDOEX campaign has yielded a 4-year average of the dry season (January to April) radiative forcing of the IndoAsian haze (Fig. 4). This haze is a $3-\mathrm{km}$ thick aerosol layer (23) that persists over most of the dry season (22) and covers most of the tropical Indian Ocean north of $5^{\circ} \mathrm{S}$ $(21,23)$. It extends over Asia into the western Pacific (22, 23) (Fig. 2A). During INDOEX, average AODs were as high as 0.3 (23), and anthropogenic sources from South Asia contributed as much as $75 \%$ to the $\operatorname{AOD}(16,22)$. The average chemical composition of the aerosols by mass included (22) sulfates $(32 \%)$, ammonium $(8 \%)$, organics $(26 \%)$, nitrates $(10 \%)$, BC $(14 \%)$, fly ash (5\%), dust $(10 \%)$, and potassium $(2 \%)$. The haze was highly absorbing with a measured SSA of about 0.9 (23).
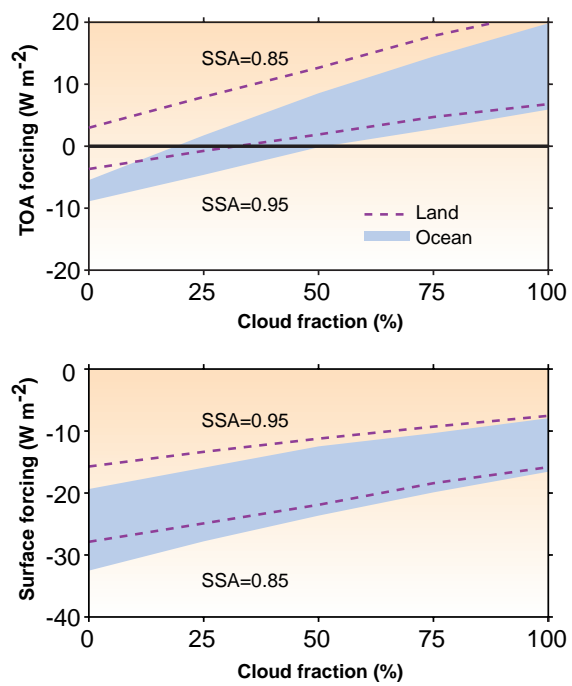

Fig. 3. Dependence of the aerosol direct forcing at the TOA (top panel) and at the surface (bottom panel) on low cloud fraction, SSA, and surface albedo (land or ocean albedo). The results are diurnally averaged and are based on a Monte Carlo aerosol-cloud-radiation model mentioned in (23). References that describe this model in detail can be seen in (23), and the model assumes an AOD of 0.3 . The SSA for the upper dashed line and the upper boundary of the blue-shaded region is 0.85 for the top panel and 0.95 for the bottom panel. A similar convention applies to the lower dashed line and the lower boundary of the blue-shaded region.
Calibrated solar radiation flux measurements from space and the surface during INDOEX revealed (16) that the haze-induced reduction in surface solar radiation (surface forcing) is three times as large as the reflected solar radiation at TOA (TOA forcing) for clear skies. It is about eight times as large for average cloudy skies (23). The large negative surface forcing of $-14 \mathrm{~W} \mathrm{~m}^{-2}$ (Fig. 4), a consequence of the large atmospheric absorption, is also typical of other polluted regions including the Atlantic (18), Eastern USA (18), the Amazon (19), and Africa (24).

\section{Indirect Radiative Forcing}

Aerosols, in particular sulfates, larger than about $0.05 \mu \mathrm{m}$ in diameter provide the nuclei for most cloud drops and ice crystals (25). Organic aerosols also serve as cloud condensation nuclei $(\mathrm{CCN})$ on a par with the role of sulfate particles (26). Trace amounts of soluble gases and organic substances in air pollution can amplify the CCN activity of small aerosols and the respective effects on clouds (27). The logical inference is that by acting as $\mathrm{CCN}$ and ice nuclei, anthropogenic aerosols have led to an increase in the number of cloud drops and ice crystals (25). This inference is borne out by observations. In situ aircraft observations (28-32) of continental and marine clouds show that anthropogenic aerosols enhance $\mathrm{CCN}$ and cloud drop number density (Fig. 5) and reduce their sizes. Satellite studies have reinforced the findings of the in situ aircraft data on larger scales (33-35). At present, there are no reliable observations of increase in cloud lifetime due to the second indirect effect. Absorbing aerosols can also lead to a surface warming through the socalled semidirect effect on clouds (36). In this effect, the solar heating of the boundary layer by BC can evaporate some of the clouds and allow more solar radiation to reach the surface.

The INDOEX cloud and aerosol data (Fig. 5 ), when integrated with realistic cloud-radiation models, yield $-5 \mathrm{~W} \mathrm{~m}^{-2}$ for the TOA forcing because of the first indirect effect (23) (Fig. 4). The global average indirect forcing (3, 8) varies from $-0.3 \mathrm{~W} \mathrm{~m}^{-2}$ to about $-1 \mathrm{~W} \mathrm{~m}^{-2}$ for just sulfate aerosols and about -0.5 to $-2 \mathrm{~W}$ $\mathrm{m}^{-2}$ for sulfate plus carbonaceous aerosols (3, 8 ). The INDOEX results and the global average model estimates both reveal that, at the TOA, the cooling effect due to the first indirect forcing is significantly larger than that due to direct forcing. At the surface, however, the direct forcing is the dominant contributor (Fig. 4).

\section{The Direct Microphysical Effect on Precipitation}

Aerosols containing large concentrations of small CCN nucleate many small cloud droplets, which coalesce very inefficiently

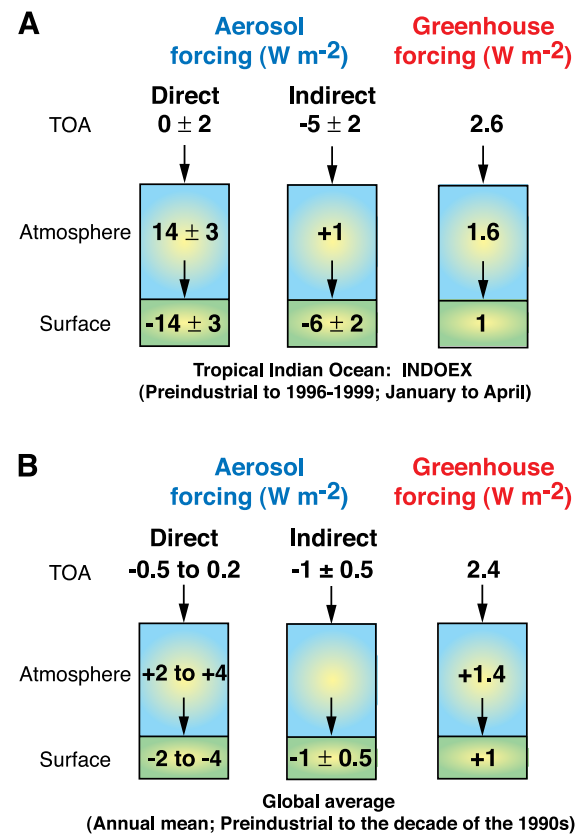

Fig. 4. Comparison of anthropogenic aerosol forcing with greenhouse forcing. (A) The IndoAsian region. Results are similar to those shown in (23) but for a much longer period. The greenhouse forcing was estimated from the NCAR community climate model (9) with an uncertainty of $\pm 20 \%$. (B) Same as above, but for global and annual average conditions. The global average values are a summary of published estimates $(3,6,8,17)$.

into raindrops. One consequence of this is suppression of rain over polluted regions (37-39). In satellite studies, the clouds within and outside of pollution tracks had similar dimensions and contained similar amounts of water $(38,39)$. The only difference was in the reduction of the cloud particle effective radius within the pollution tracks to less than $14 \mu \mathrm{m}$ (Fig. 6), the precipitation threshold radius below which precipitation particles do not normally form $(38,39)$. Precipitation was observed only outside the pollution tracks, not in them. The suppression of coalescence by smoke and air pollution also induced lower freezing temperature of the cloud supercooled water and suppression of the ice precipitation processes (39). Desert dust also suppresses precipitation from warm clouds, but in addition, it has a strong ice-nucleating activity (40). The effect on precipitation has been documented so far only on the basis of case studies, but it is likely to be a major factor in reducing precipitation efficiency of clouds over land where anthropogenic sources are a major source of $\mathrm{CCN}$.

\section{Response of the Climate System}

Greenhouse gases and aerosols have competing effects on climate and the hydrological cycle. Furthermore, their competing effects 


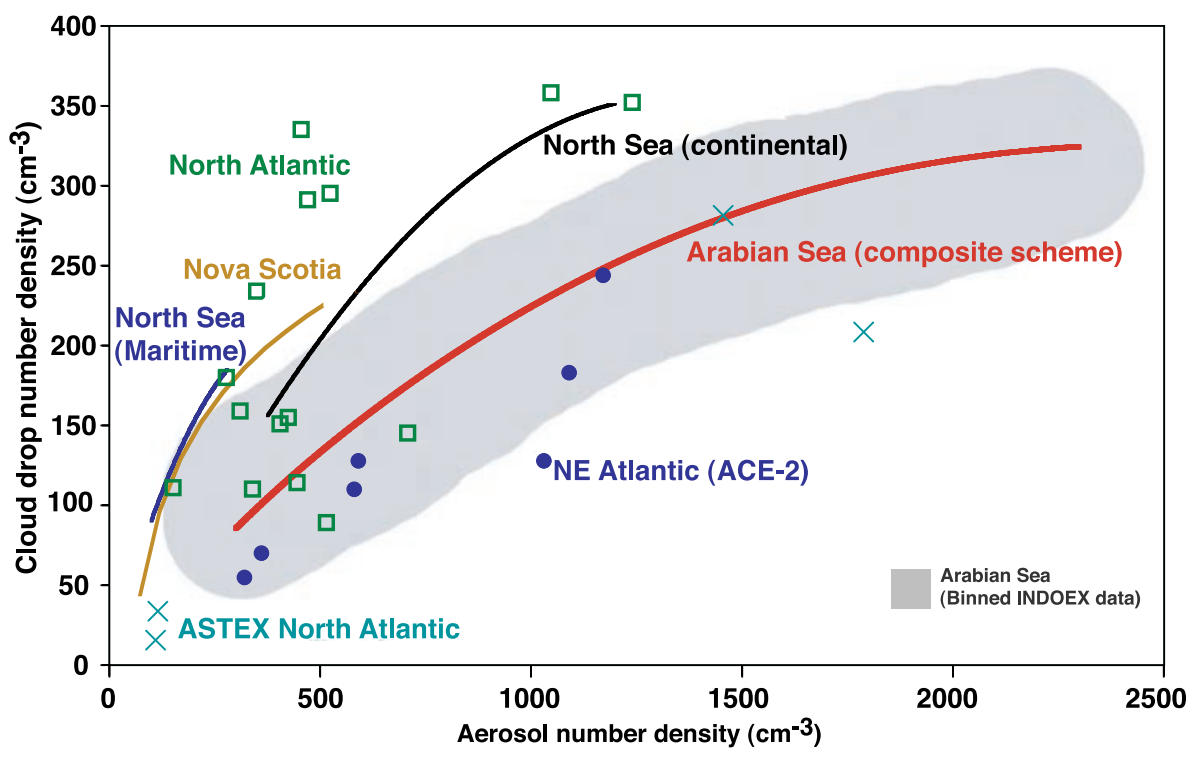

Fig. 5. Aircraft data illustrating the increase in cloud drops with aerosol number concentration. References for the data are as follows: North Sea (28), Nova Scotia and North Atlantic (29), ACE-2 (30), Astex (31), the thick red line is obtained from a composite theoretical parameterization that fits the INDOEX aircraft data for the Arabian Sea (23). The gray-shaded region is the INDOEX aircraft data for the Arabian Sea (32).

depend on spatial and temporal scales. We will begin with the global mean impacts.

Impact on global surface temperature. Numerous coupled ocean and atmosphere general circulation climate models (OAGCMs) have shown that the global average temperature changes are largely determined by the TOA forcing $(8)$. It then follows from the TOA forcing values in Fig. 4 that the global surface warming due to GHGs should exceed the global cooling effect of the aerosols; regionally, however, the aerosols' cooling effects could exceed the GHG's warming as discussed later. Modern climate models suggest that the global surface would warm by about 0.5 to $0.8 \mathrm{~K}$ per $1 \mathrm{~W} \mathrm{~m}^{-2}$ TOA forcing $(6,8,36)$. Out of the $2.4 \mathrm{~W} \mathrm{~m}^{-2} 20$ th century anthropogenic GHG forcing, about $0.4 \mathrm{~W} \mathrm{~m}^{-2}$ is stored in the oceans $(41)$; the remaining $2 \mathrm{~W} \mathrm{~m}^{-2}$ should have caused a warming of about 1 to $1.6 \mathrm{~K}$. The observed warming between 1900 and 2000 is only about $0.6 \mathrm{~K}(36)$. The estimated global mean TOA aerosol forcing of $-1 \pm 0.5 \mathrm{~W} \mathrm{~m}^{-2}$ (Fig. 4) is sufficient to account for the missing cooling effect. However, the observed warming occurred during two episodes, one from 1900 to 1940 and the other from 1975 onward, with a slight cooling trend in between. This indicates that other factors such as volcanoes and solar variations $(8,36)$ are also involved.

Impact on the global hydrological cycle. Most, if not all, OA-GCMs show that a global mean surface warming will be accompanied by an increase in global precipitation (42) by about 1 to $2 \%$ per Kelvin (increase in surface temperature) because of the increase in evap- oration, particularly from the oceans. The evaporation increases because the saturation vapor pressure increases with temperature. The large difference between TOA and surface forcing due to the absorbing anthropogenic aerosols raises an important question related to the hydrological cycle: How does the system adjust to the large reduction in surface solar absorption (Figs. 4 and 7)? Long-term negative trends in surface solar irradiance have been observed by surface radiometers worldwide over land $(43,44)$. The reported trends in the annual mean irradiance vary from $-5 \%\left(10 \mathrm{~W} \mathrm{~m}^{-2}\right)$ between 1958 to 1985 for all land stations (43) to about -1 to $-3 \%$ per decade for the last 4 decades over many of the 1500 stations in the global data sets (44). It should be noted, however, that surface radiometric observations are subject to large uncertainties. Furthermore, the observed changes may not be solely due to aerosols.

At the surface, there is a balance between radiation, evaporation (latent heat flux from the surface to the atmosphere), and sensible heat flux. One or all of these components will decrease to compensate for the reduction in surface solar radiation. Sixty to 70 percent of the absorbed solar radiation at the surface is balanced (on a global annual mean basis) by evaporation (9), and it is thus possible that a major fraction of the reduction in surface solar radiation (Figs. 4 and 7) is balanced by a reduction in evaporation. Reduction in the evaporation will have to be balanced by a reduction in rainfall and effectively spin down the hydrological cycle.

We do not have global model studies of realistic absorbing aerosols to assess the quantitative importance of the aerosol effect on the hydrological cycle. However, the deduction regarding the hydrological cycle spin-down is supported by numerous OAGCM studies (45-48). Most models have included only the radiative effect of sulfate aerosols. Inclusion of just the direct radiative forcing of sulfate aerosols (without GHG forcing) leads to a net reduction in the hydrologic cycle, with the reduction in solar insolation balanced partially by a reduction in the latent heat flux due to evaporation. In more recent studies $(47,48)$, which include both the direct and the indirect radiative effect of sulfate aerosols, the strength of the hydrologic cycle also decreased, and this decrease was large enough to reverse the effect of GHGs in one of the models (48).

Regional climate changes. Regionally, particularly in the tropics and subtropics with highly absorbing particles during the dry season, anthropogenic aerosols can decrease the average solar radiation absorbed by the surface by as much as 15 to $35 \mathrm{~W} \mathrm{~m}^{-2}$ (Fig. 7) and can increase the atmospheric heating, within the lowest 3 kilometers of the atmosphere, by as much as 60 to $100 \%$ (Fig. 7). Perturbations similar to those shown in Fig. 7 should also be expected in other regions (East

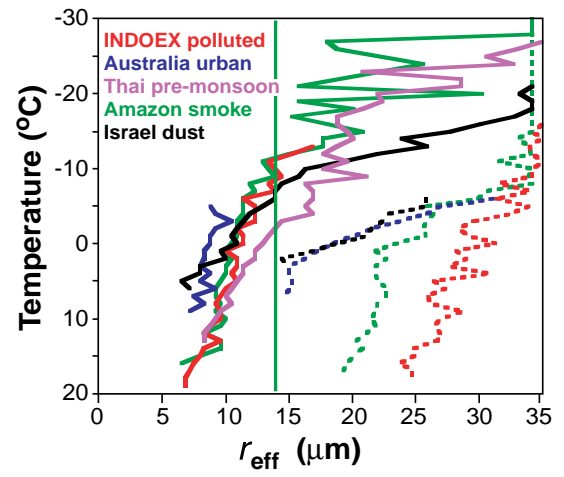

Fig. 6. Satellite-retrieved median effective radius of particles near the top of deep convective clouds at various stages of their vertical development, as a function of the cloud top temperature, which serves as a surrogate for cloud top height. The effective radius is the ratio of the integral of the third moment $\left(r^{3}\right)$ of the radius, weighted with the number concentration at that radius, to its second moment $\left(r^{2}\right)$. This is shown for clouds forming in polluted (solid lines) and pristine air (broken lines). The red lines denoted by "INDOEX polluted" are for data along a track that runs from South West India into the Indian Ocean. The blue lines are for tracks over urban Southeastern Australia (38). Violet lines are for Thailand pre-monsoon clouds with suppressed coalescence. Green lines are for biomass smoke over the Amazon; and black lines are for desert dust over Israel (40). The vertical green line denotes the $14-\mu \mathrm{m}$ precipitation threshold radius. The references that justify this threshold value are given in $(38,39)$. 


\section{SCIENCE'S COMPASS}

Asia, South America, sub-Saharan Africa, and parts of Europe) subject to large loading of absorbing aerosols (Fig. 2A). The impact of aerosols that is more significant than the TOA forcing involves the vertical redistribution of the solar radiation between the surface and the lower atmosphere, qualitatively resembling the nuclear winter forcing (49). Such a perturbation, during the dry season, can lead to a large regional cooling at the surface accompanied by a warming of the lower troposphere as shown in the GCM study (with fixed ocean surface temperature) reported in (23). The lower atmosphere of the GCM over the tropical Indian Ocean warmed by about $1 \mathrm{~K}$, and the land surface cooled by about 0.5 to $1 \mathrm{~K}$. Regional aerosol cooling in Northern Hemisphere mid-latitudes have also been estimated by GCMs (but including only sulfates) $(47,48)$. Although the large cooling observed (42) over the Northern Hemisphere land masses during the 1940s to 1970 s is consistent with the large increase in sulfate aerosol emissions, we cannot rule out other natural causes. It is also interesting that, even though the heat content of most of the world's oceans increased during the last century, the North Indian Ocean (see the large reduction in solar radiation shown in Fig. 7) was the major exception (41).

The largest impact of the INDOEX aerosols is to alter the latitudinal and interhemispheric gradients in solar heating (Fig. 7), which play a dominant role in driving the tropical circulation. In addition, the direct microphysical effect might decrease rainfall beyond the reduction in evaporation, because on a regional scale, precipitation does not have to balance evaporation. This effect may be most evident in regions of heavy aerosol loading (Fig. 2C) and at low latitudes, where the convective nature of the clouds renders them susceptible to the suppression effects. This might account for the observation (42) that rainfall has decreased over much of the Northern Hemisphere subtropical $\left(10^{\circ} \mathrm{N}\right.$ to $\left.30^{\circ} \mathrm{N}\right)$ land areas during the 20th century by about $0.3 \%$ per decade, whereas the precipitation in the mid- and high latitudes has increased by about 0.5 to $1 \%$ per decade, except over East Asia. The exception is interesting, because East Asia is one of the most polluted regions (Fig. 2, $A$ and $C$ ). Furthermore, the increase in tropical land-surface precipitation witnessed during most of the 20th century (42) was not evident over the past few decades, when anthropogenic aerosol emission rates increased significantly in the tropics. However, greenhouse forcing can

also explain some of these observed changes. OA-GCMs with GHG forcing estimate an increase of precipitation in mid- to high latitudes, a decrease in subtropical regions, and an increase in tropical regions $(45,47)$.

Feedbacks. The impact of the aerosols can also be enhanced by feedback loops. The main mechanism for cleansing the atmosphere from aerosols is deposition by precipitation. The suppression of precipitation by aerosols prolongs their atmospheric residence time, further enhancing their impacts. The drier conditions due to the suppressed rainfall are conducive to raising more dust and smoke

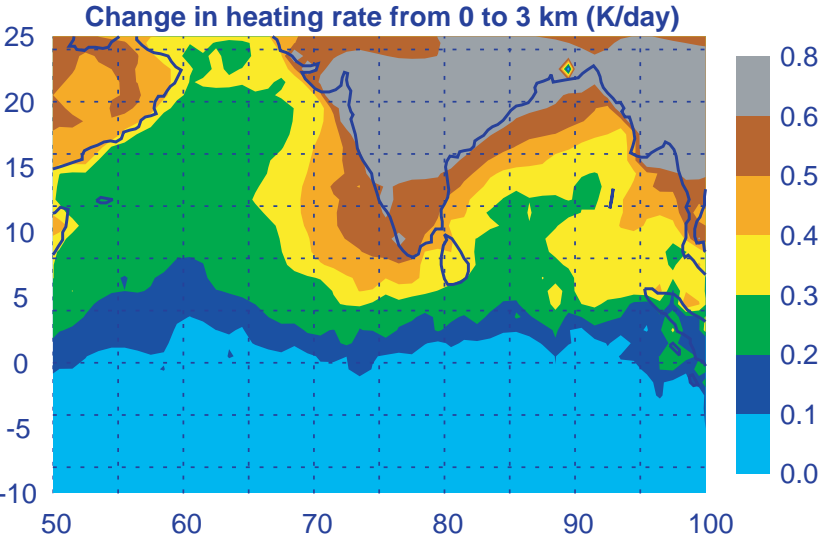

Change in absorbed surface solar radiation $\left(\mathrm{W} \mathrm{m}^{-2}\right)$

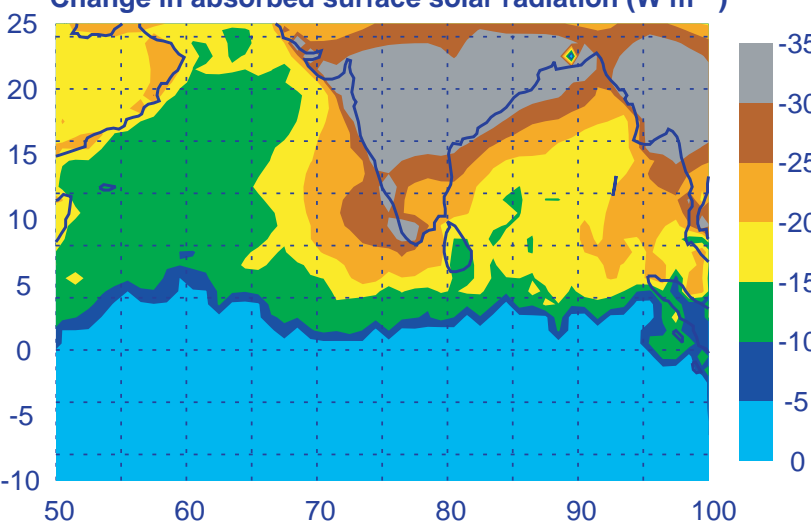

Fig. 7. The Indo-Asian haze effects on seasonal mean (January to April for 1996 to 1999) change in atmospheric solar heating rate (top panel) and the reduction in surface solar radiation (bottom panel). Results are similar to those shown in (23), but for a much onger period.

from burning of the drier vegetation. Suppression of precipitation in the updrafts of very deep clouds, especially in the tropics, can also transport more water and aerosols into the upper troposphere and the lower stratosphere. The accompanying increase in the upper troposphere water vapor greenhouse effect can counter some of the aerosol cooling effect.

\section{Implications for the Future}

It is important to differentiate the decadal to centennial time scales involved in GHG warming from the time scale of aerosol lifetimes, which is only several days [Web table 1 (1)]. On the regional scale, anthropogenic aerosols are already affecting surface forcing, atmospheric heating, and precipitation. Here, we have emphasized the hitherto underestimated impact of aerosols on Earth's radiation at the surface and on the hydrological cycle on global and regional scales. Globally averaged, the aerosol net radiative cooling effect at present may be quite comparable with the forcing due to GHG emissions. The role of GHGs in global warming will increase because of their accumulation in the atmosphere (8). For the next decades, the regional aerosol effects will continue to play a major role as long as such strong sources of air pollution remain. It appears that the strongest GHG effect (on surface temperature) will be felt in the Southern Hemisphere and at the extra-tropical latitudes, whereas the effects from aerosols will be felt most in the tropics and the subtropics, particularly in view of the large tropical and subtropical aerosol emission sources in the Asian region (Fig. 2).

\section{Directions for Future Research}

First and foremost, we need a reliable global inventory of aerosol emission rates, lifetimes, and concentrations. BC emissions from Asia are particularly important. We urgently need the capability to observe the global distribution and transport of BC around the planet. We also need reliable measurements of AODs over land, because current long-term satellite observations are reliable only over the ocean. Such data are within reach $[(4,50)$; see also MODIS land AOD in Fig. 2A]. On the theoretical and experimental side, we need to investigate how carbonaceous aerosols regulate the microphysical processes in clouds. We also need carefully designed OAGCM studies to determine how the hydrological cycle responds to the microphysical and radiative effects of aerosols. Integration of innovative new satellite observations, field experiments, and laboratory studies with models will pave the way for breakthroughs in our understanding of how these tiny particles are modifying the environment.

\section{References and Notes}

1. Web figs. 1 and 2, Web table 1 , and supplemental text are available on Science Online at www.sciencemag.org/ cgi/content/full/294/5549/2119/DC1.

2. J. E. Penner et al., in Climate Change 2001: The Scientific Basis [Working Group I to the Third Assess- 


\section{SCIENCE'S COMPASS}

ment Report of the Intergovernmental Panel on Climate Change (IPCC), Cambridge Univ. Press, Cambridge, 2001], pp. 289-348.

3. J. Haywood, O. Boucher, Rev. Geophys. 38, 513 (2000).

4. Y. J. Kaufman et al., J. Geophys. Res. 102, 17051 (1997).

5. W. D. Collins et al., J. Geophys. Res. 106, 7313 (2001)

6. J. E. Hansen, M. Sato, R. Ruedy, J. Geophys. Res. 102, 6831 (1997).

7. A. Robertson et al., J. Geophys. Res. 106, 14783 (2001).

8. V. Ramaswamy et al., in Climate Change 2001: The Scientific Basis (Working Group I to the Third Assessment Report of the IPCC, Cambridge Univ. Press, Cambridge, 2001), pp. 349-416.

9. J. T. Kiehl, K. E. Trenberth, Bull. Am. Meteorol. Soc. 78, 197 (1997)

10. P. J. Crutzen, M. O. Andreae, Science 250, 1669 (1990).

11. R. J. Charlson, J. Langner, H. Rodhe, C. B. Leovy, S. G. Warren, Tellus 43AB, 152 (1991)

12. A. D. Clarke, R. J. Charlson, Science 229, 263 (1985).

13. H. Grassl, Beitr. Phys. Atmos. 48, 199 (1975).

14. J. A. Ogren, R. J. Charlson, Tellus 35B, 241 (1983).

15. A. Jayaraman et al., J. Geophys. Res. 103, 13827 (1998).

16. S. K. Satheesh, V. Ramanathan, Nature 405, 60 (2000).

17. M. J. Jacobson, J. Geophys. Res. 106, 1551 (2001)

18. P. B. Russell et al., J. Geophys. Res. 104, 2289 (1999)

19. T. F. Eck, B. N. Holben, I. Slutsker, A. Setzer, J. Geophys. Res. 103, 31865 (1998).
20. F. Raes, T. Bates, F. McGovern, M. Van Liedekerke, Tellus 52B, 111 (2000).

21. K. Rajeev, V. Ramanathan, J. Meywerk, J. Geophys. Res. 105, 2029 (2000).

22. J. Lelieveld et al., Science 291, 1031 (2001).

23. V. Ramanathan et al., J. Geophys. Res. 106, 28371 (2001).

24. T. Konzelmann, D. R. Cahoon, C. H. Whitlock, Geophys. Res. 101, 22833 (1996).

25. S. Twomey, Atmos. Environ. 8, 1251 (1974).

26. T. Novakov, J. E. Penner, Nature 365, 823 (1993).

27. R. J. Charlson et al., Science 292, 2025 (2001).

28. G. M. Martin, W. Johnson, A. Spice, J. Atmos. Sci. 51, 1823 (1994)

29. I. Guiltepe, G. A. Issac, W. R. Leaitch, C. M. Banic, J. Clim. 9, 345 (1996).

30. H. Pawlowska, J.-L. Brenguier, Tellus 52B, 868 (2000).

31. J. P. Taylor, A. McHafffie, J. Atmos. Sci. 51, 1298 (1994).

32. G. A. McFarquhar, A. Heymsfield, J. Geophys. Res., in press.

33. J. A. Coakley, R. L. Bernstein, P. A. Durkey, Science 237, 1020 (1987).

34. Y. J. Kaufman, R. S. Fraser, Science 277, 1636 (1997).

35. T. Nakajima, A. Higurashi, K. Kawamoto, J. E. Penner, Geophys. Res. Lett. 28, 1171 (2001).

36. J. Hansen, M. Sato, R. Ruedy, A. Lacis, V. Oinas, Proc. Natl. Acad. Sci. U.S.A. 97, 9875 (2000).

37. J. J. Warner, J. Appl. Meteorol. 7, 247 (1968)

38. D. Rosenfeld, Geophys. Res. Lett. 26, 3105 (1999).

39. _ Science 287, 1793 (2000).

40. __ Y. Rudich, R. Lahav, Proc. Natl. Acad. Sci. U.S.A. 98, 5975 (2001).

41. S. Levitus et al., Science 292, 267 (2001).
42. C. K. Folland et al., in Climate Change 2001: The Scientific Basis (Working Group I to the Third Assessment Report of the IPCC, Cambridge Univ. Press, Cambridge, 2001), pp. 99-181.

43. G. Stanhill, S. Cohen, Agric. For. Meteorol. 107, 255 (2001).

44. H. Gilgen, M. Wild, A. Ohmura, J. Clim. 11, 2042 (1998).

45. V. Ramaswamy, C. T. Chen, Geophys. Res. Lett. 24 567 (1997).

46. G. A. Meehl, W. M. Washington, D. J. Erickson III, B. P. Briegleb, P. J. Jaumann, Geophys. Res. Lett. 23, 3755 (1996).

47. J. F. B. Michell, T. C. Johns, J. Clim. 10, 245 (1997).

48. E. Roeckner, L. Bengtsson, J. Feichter, J. Lelieveld, H. Rhode, J. Clim. 12, 3004 (1999).

49. P. J. Crutzen, J. Birks, Ambio 11, 114 (1982).

50. M. D. King, Y. J. Kaufman, D. Tanre, T. Nakajima, Bull. Am. Meteorol. Soc. 80, 2229 (1999)

51. M. O. Andreae, P. J. Crutzen, Science 276, 1052 (1997).

52. This work was funded by the National Science Foundation (the lead agency for INDOEX), the Department of Energy, the Vetlesen Foundation, and NASA. We thank W. D. Collins, A. Chu, J. Hansen, A. Heymsfield, Y. Kaufman, G. MacFarquhar, I. Podgorny, V. Ramaswamy, and M. Sato for generously providing their results; A. Andreae, J. Lelieveld, and T. Novakov for discussions; two anonymous reviewers for their detailed comments on an earlier version of the paper; and C. Jehl, J. des Rosiers, and L. Ding for help with the manuscript and the illustrations.

those around the world) can eliminate the information gap between when Science publishes and when it arrives in the post. This free enhancement to your Science Online subscription delivers e-mail summaries of the latest news and research articles published each Friday in Science-instantly. To sign up for the Content Alert service, go to Science Online and eliminate the gap.

\section{Science \\ www.sciencemag.org}

For more information about Content Alerts go to www.sciencemag.org. Click on Subscription button, then click on Content Alert button. 